Short Communication

\title{
Electrochemical Performance of Activated Carbons with Different Specific Surface Area as Supercapacitor Electrode Materials
}

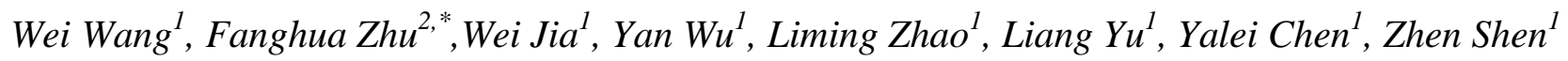 \\ ${ }^{1}$ School of Materials Science and Engineering, Southwest University of Science and Technology, \\ Mianyang 621010, China. \\ ${ }^{2}$ Research Center of Laser Fusion, China Academy of Engineering Physics, Mianyang, Sichuan \\ 621900, China. \\ *E-mail: fanghuazhu@sina.com
}

doi: $10.20964 / 2016.08 .40$

Received: 18 March 2016 / Accepted: 23 May 2016 / Published: 7 July 2016

In this paper, we chose commercial activated carbons (AC) as electrode materials because the advantage of abundant in raw, lower price and larger specific surface area. First, we characterized the physical properties of these two ACs. Second, we utilized these ACs to prepare electrode as working electrodes and characterized in the $1 \mathrm{~mol} / \mathrm{L} \mathrm{H}_{2} \mathrm{SO}_{4}$, The results indicated that the specific surface of 1$\mathrm{AC}$ and 2-AC are $758 \mathrm{~m}^{2} / \mathrm{g}$ and $1771 \mathrm{~m}^{2} / \mathrm{g}$ respectively. The tests of electrochemical capacitance performance indicated that the specific capacitance of electrode increased with the specific surface area increasing. And both electrochemical stability retained over $90 \%$ of the original capacitance.

Keywords: activated carbon; supercapacitor; electrode material

\section{FULLTEXT}

(C) 2016 The Authors. Published by ESG (www.electrochemsci.org). This article is an open access article distributed under the terms and conditions of the Creative Commons Attribution license (http://creativecommons.org/licenses/by/4.0/). 